\title{
Culture media optimization for Chinese hamster ovary cell growth and expression of recombinant varicella-zoster virus glycoprotein $\mathbf{E}$
}

\author{
Kwang Sung Kim $\cdot$ Shin Ae Park $\cdot$ Seo Ri Wui $\cdot$ Ara Ko $\cdot$ Na Gyong Lee $\mathbb{C}$
}

Received: 8 October 2020/ Accepted: 31 March 2021/Published online: 20 April 2021

(C) The Author(s), under exclusive licence to Springer Nature B.V. 2021

\begin{abstract}
Herpes zoster (HZ) is caused by reactivation of varicella-zoster virus (VZV) latent in the sensory ganglia and causes severe pain, often leading to postherpetic neuralgia (PHN). Two prophylactic vaccines against $\mathrm{HZ}$ are currently licensed for human use, a live attenuated vaccine and a subunit vaccine containing recombinant VZV glycoprotein E (gE) as antigen. The latter has superior protective efficacy against HZ and PHN. During HZ subunit vaccine development, we obtained Chinese hamster ovary (CHO) cell clones expressing VZV gE. This study was performed to optimize culture media conditions for
\end{abstract}

Supplementary Information The online version contains supplementary material available at https://doi.org/10.1007/ s10616-021-00468-1.

K. S. Kim · S. R. Wui · A. Ko · N. G. Lee $(\square)$

Department of Integrated Bioscience \& Biotechnology,

Sejong University, 209 Neungdong-ro, Gwangjin-gu,

Seoul 05006, Republic of Korea

e-mail: nglee@sejong.ac.kr

K. S. Kim

e-mail: black@eyegene.co.kr

S. R. Wui

e-mail: ehwls4144@naver.com

A. Ko

e-mail: jellyz47@naver.com

K. S. Kim · S. A. Park

R\&D Center, EyeGene, Goyang 10551, Republic of

Korea

e-mail: gold@eyegene.co.kr
$\mathrm{CHO}$ cell growth and gE production. Using a highthroughput culture system, three $\mathrm{CHO}$ cell clones were cultured in microtiter plates containing 24 different basal media, and three basal media were selected. The clone with the highest $\mathrm{gE}$ expression was fed-batch cultured in each of the three basal media in combination with 13 different feed media. A pair of media, BalanCD CHO Growth A and EX-CELL Advanced CHO Feed 1, with the highest productivity was selected for $\mathrm{gE}$ production. Scale-up fed-batch cultures of the selected clone cultured in a wave bag bioreactor containing the optimized media yielded $2440 \mathrm{mg}$ gE protein/L culture, a 11.5-fold increase compared to original culture conditions (batch culture in CD OptiCHO medium). The optimized media condition is used to produce VZV gE antigen for an $\mathrm{HZ}$ subunit vaccine, which is under phase I clinical trial. This study would provide valuable insights on culture media optimization for $\mathrm{CHO}$ cells expressing a recombinant vaccine antigen.

Keywords Chinese hamster ovary $(\mathrm{CHO})$ cell clone $\cdot$ Fed-batch culture $\cdot$ Culture media optimization - Varicella-zoster virus glycoprotein E . Vaccine antigen $\cdot$ Immunogenicity 


\section{Introduction}

Varicella-zoster virus (VZV) is an $\boldsymbol{\alpha}$-herpesvirus that causes two distinct diseases, varicella and herpes zoster (HZ) (Zerboni et al. 2014). At a primary infection, VZV causes varicella in young children and becomes latent VZV in sensory ganglia. Reactivation of latent VZV causes painful HZ in elderly people, occasionally leading to a serious complication, postherpetic neuralgia (PHN) (Zerboni et al. 2014). Currently, two $\mathrm{HZ}$ vaccines are available for human use (Cunningham and Levin 2018). A live attenuated vaccine (LAV) was the first vaccine licensed for prevention of $\mathrm{HZ}$ and PHN. However, this vaccine has a low protective efficacy against $\mathrm{HZ}$ and PHN (70\%), and the efficacy decreases with age; the protection rate is $41 \%$ in people $>70$ years of age (Hales et al. 2014; Levin et al. 1992; Oxman et al. 2005). Recently, a recombinant $\mathrm{HZ}$ subunit vaccine was approved for human use. It consists of truncated recombinant VZV glycoprotein $\mathrm{E}(\mathrm{gE})$ protein expressed in Chinese hamster ovary $(\mathrm{CHO})$ cells and the adjuvant system AS01B (James et al. 2018). The HZ subunit vaccine has a higher protective efficacy; the protection rate against $\mathrm{HZ}$ is $97.2 \%$ in individuals $>50$ years of age old and the protection is longer-lasting (Chlibek et al. 2016; Cunningham et al. 2018; Lal et al. 2015).

CHO cells are a preferred mammalian expression system for recombinant protein production in the biopharmaceutical industry. The resulting target proteins are stable and high-output. The system is scalable and meets post-translational processing requirements (Jayapal et al. 2007; Ozturk and $\mathrm{Hu}$ 2005; Wurm 2004). In the pharmaceutical development process, improving protein productivity in mammalian cell culture is essential to reduce production costs. This objective can be achieved by establishment of highly productive clones, optimization of cell culture conditions, and development of efficient large-scale manufacturing processes (Kelley 2009; Wurm 2004). Culture medium development is critical for optimizing cell growth profile and productivity of $\mathrm{CHO}$ cells (Ritacco et al. 2018). CHO cell culture media have evolved from serum-containing to serum-free to chemically-defined synthetic media (Ozturk and $\mathrm{Hu}$ 2005; Ritacco et al. 2018). However, designing a chemically-defined medium is a labor-intensive and time-consuming process. Many media for $\mathrm{CHO}$ cell culture are commercially available, allowing developers to choose the optimal blend of media components to achieve the best balance between high cell growth and productivity (Ma et al. 2009; Rodrigues et al. 2012).

Fed-batch culture is mainly used in the biopharmaceutical industry to increase bioreactor productivity. During the fed-batch process, cells are inoculated and cultured in a basal medium that supports initial cell growth, followed by addition of a feed medium at a specific stage of growth to prevent nutrient depletion. In general, feed media are more concentrated than basal media to maximize product titers. The compositions of basal and feed media affect cell metabolism and growth, gene expression, and protein productivity and quality (Kyriakopoulos and Kontoravdi 2014; Lu et al. 2013; Ma et al. 2009; Reinhart et al. 2015; Rodrigues et al. 2012). Optimal medium composition also varies depending on the CHO cell line, generated clones, and target protein type (Pan et al. 2017; Reinhart et al. 2015; Rodrigues et al. 2012). No single basal or feed medium is suitable for all $\mathrm{CHO}$ cell clones.

In a previous study, we developed a recombinant $\mathrm{HZ}$ subunit vaccine that consists of recombinant VZV $\mathrm{gE}$ antigen and the adjuvant system CIA09A, and demonstrated that the vaccine efficiently induced both humoral and cellular immune responses in mice (Wui et al. 2019). During the development process, we obtained three $\mathrm{CHO}$ cell clones expressing recombinant VZV gE protein. The objective of this study was to optimize culture conditions for growth and target protein productivity of $\mathrm{CHO}$ cell clones.

\section{Materials and methods}

\section{Construction of CHO cell clones expressing VZV $\mathrm{gE}$}

To construct a plasmid expressing VZV gE, the codon-optimized DNA sequence encoding the truncated VZV gE lacking the hydrophobic anchor and carboxy-terminal domains (546 amino acids) was chemically synthesized (Fig. 1a) and cloned into the EcoRI and $X b a \mathrm{I}$ sites of $\mathrm{pGN}-\mathrm{M}$ vector containing the CMV promoter and the dihydrofolate reductase gene (GenScript, NJ, USA), yielding the expression plasmid pGN-M_VZV gE as shown in Fig. 1b. CHO DG44 cells (Urlaub et al. 1983) were transfected with 
Fig. 1 Construction of the plasmid expressing VZV $\mathrm{gE}$ protein. The DNA sequence encoding the truncated VZV $\mathrm{gE}$ lacking the hydrophobic anchor and carboxyterminal domains (546 amino acids) (a) was cloned into the EcoRI and $\mathrm{XbaI}$ sites of pGN-M vector, yielding the expression plasmid pGN-M_VZV gE (b)

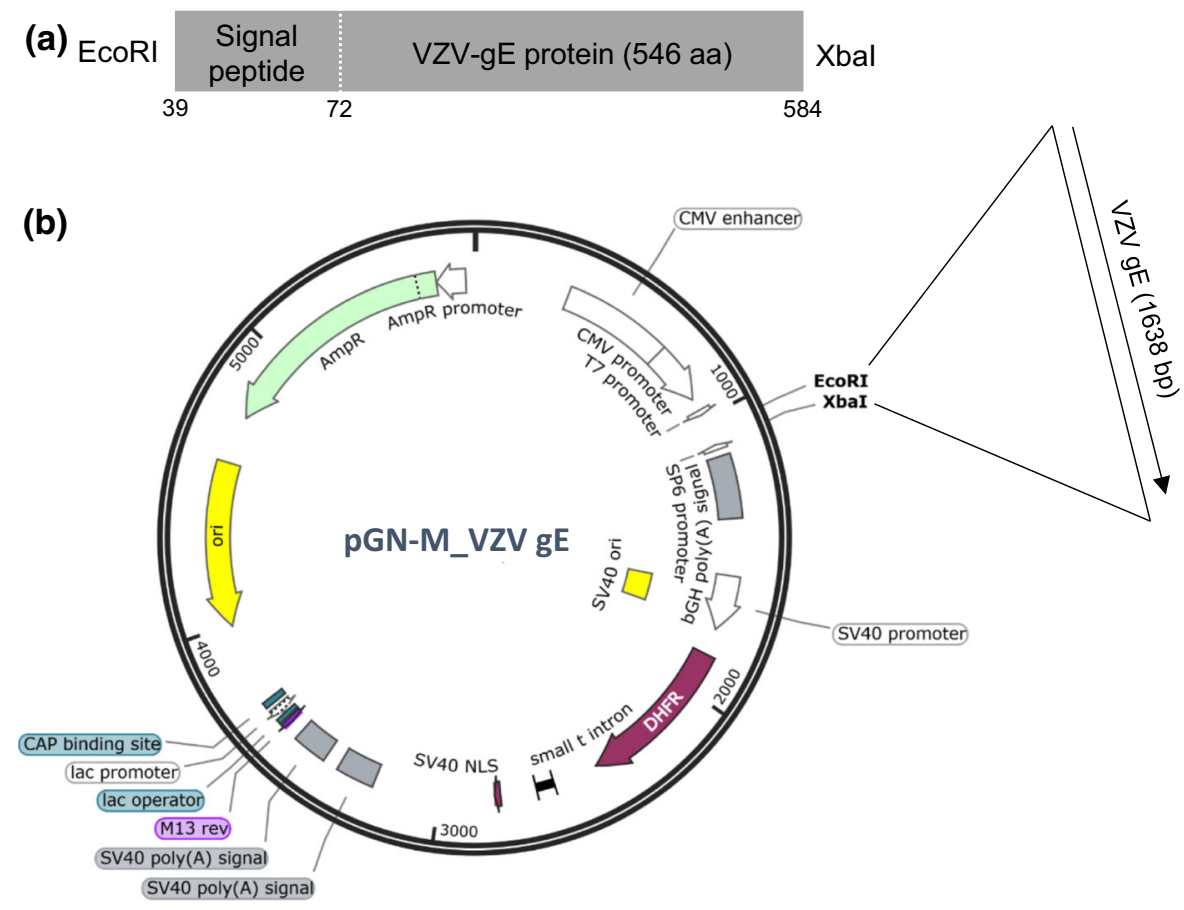

pGN-M_VZV gE by electroporation, and transfectants were cultured in CD-Opti-CHO medium (Thermo Fisher Scientific, MA, USA) supplemented with $8 \mathrm{mM}$ L-glutamine (GE Healthcare Life Sciences, PA, USA), $0.018 \%$ F-68 (Thermo Fisher Scientific, MA, USA). CHO cell clones were screened for recombinant $\mathrm{VZV} \mathrm{gE}$ expression by dot blot and immunoblot analyses of culture supernatants, followed by four rounds of gene amplification using MTX. CHO cell clones expressing high levels of VZV $\mathrm{gE}$ were selected, and three clones showing the highest expression levels (\#23-125, \#23-136, and \#83-110) were used in this study.

Cell culture media

Cells were maintained in $30 \mathrm{~mL}$ CD OptiCHO medium supplemented with $8 \mathrm{mM}$ L-glutamine and $0.1 \%$ Pluronic F-68 in a $125-\mathrm{mL}$ flask. The cells were cultured in a $37{ }^{\circ} \mathrm{C}$ incubator under a $5 \% \mathrm{CO}_{2}$ atmosphere with agitation at $120 \mathrm{rpm}$. The 24 chemically-defined basal media and 13 chemically-defined feed media tested for culture media optimization were provided by the New Drug Development Center of Osong Hi-Tech Medical Industry Promotion Foundation (Osong, Chungbuk, Korea). All basal media were supplemented with $8 \mathrm{mM}$ L-glutamine and $0.1 \%$ Pluronic F-68.

Batch and fed-batch cultures in microtiter plates

Culture medium screening was performed using a high-throughput culture system at the New Drug Development Center of Osong Hi-Tech Medical Industry Promotion Foundation. Small-scale batch cultures were carried out in 24-square deep-well microtiter plates using a Micro-Flask system (Applikon Biotechnology, CA, USA). Cells pre-cultured in flasks were added to each well at a density of $0.5 \times 10^{6}$ cells $/ \mathrm{mL}$ basal medium. The plates were incubated at $37{ }^{\circ} \mathrm{C}$ under a $5 \% \mathrm{CO}_{2}$ atmosphere with agitation at $235 \mathrm{rpm}$ for 7 days. Ten percent of the culture medium was removed from each well for analysis at days $0,1,3,5$, and 7 , and the same volume of fresh medium was added to the culture. Recombinant VZV gE protein levels of culture media were determined at day 7 .

For fed-batch cultures, cells were inoculated in basal media in microtiter plates and cultured for 11 days. Ten percent of the culture medium was removed from each well for analysis at days 3, 5, 7, and 9 , and each culture was then fed with the same 
volume of feed medium. Recombinant $\mathrm{gE}$ protein levels of culture media were determined at day 11 .

Measurement of cell density, and viability

Cells were stained with trypan blue or propidium iodide. Total cell density, viable cell density (VCD), and cell viability (VIA) were measured using a Vi-Cell XR cell viability analyzer (Beckman Coulter, CA, USA) or Guava easyCyte 8HT flow cytometer (Merck, NJ, USA).

Flask and bioreactor cultivation

For flask cultures, initial batch cultures were performed with $200 \mathrm{~mL}$ basal medium in a $1 \mathrm{~L}$ Erlenmeyer flask with an agitation at $120 \mathrm{rpm}$ at $37{ }^{\circ} \mathrm{C}$ in a $5 \% \mathrm{CO}_{2}$ incubator. Feed media were added to the cultures at $10 \%$ of culture volume at days $3,5,7,9$, and 11. Aliquots of culture medium $(0.2 \mathrm{~mL})$ were taken every day to determine VCD and VIA values. Recombinant $\mathrm{gE}$ protein levels of culture media were determined at day 14 .

For a scale-up culture, cells were inoculated at a density of $0.5 \times 10^{6}$ cells $/ \mathrm{mL}$ in $15 \mathrm{~L}$ basal media in a $20 \mathrm{~L}$ wave bag. They were then cultured for 13 days using a wave bag bioreactor system (Sartorius, Göttingen, Germany). Feed medium was added to each culture at $10 \%$ of the start culture volume on days $2,4,6$, and 8 . The temperature was $37 \pm 0.5{ }^{\circ} \mathrm{C}$, and the aeration rate was $1 \mathrm{~L} / \mathrm{min}$ with a dissolved oxygen level $>50 \%$. The $\mathrm{pH}$ was set to $7.1 \pm 0.15$. The rocking speed was $20 \mathrm{rpm}$ with a stirring angle of 9 degrees. Culture medium was removed every day and assayed for VCD, VIA, and gE content.

\section{Purification of recombinant VZV gE protein}

Recombinant gE protein accumulated in culture media was purified by anion exchange chromatography using Q Sepharose (Cytiva Life Science, MA, USA), followed by ultrafiltration. To confirm the size and purity of the purified protein, gE protein was quantified using the Bradford assay and resolved on $10 \%$ NuPAGE Bis-Tris protein gels (Thermo Fisher Scientific, MA, USA) in a non-reducing condition, followed by Coomassie Brilliant Blue (CBB) staining and densitometry. For identification, immunoblot analysis was carried out using mouse anti-VZV $\mathrm{gE}$ antibody (Virusis, MA, USA). Endotoxin content was determined using the Endosafe-PTS test system (Charles River Laboratories, MA, USA) and was confirmed to be $<1 \mathrm{EU} / \mu \mathrm{g}$ protein.

Size exclusion-high performance liquid chromatography for gE quantification

Recombinant VZV gE protein levels of culture media were analyzed by size exclusion-high performance liquid chromatography (SEC-HPLC) (Agilent 1260 HPLC, Agilent, CA, USA). A TSKgel G3000 SW XL column and a TSKgel guard column (Tosoh Bioscience, Tokyo, Japan) were used for protein separation. Sodium citrate (100 mM, pH 6.0) was used for the mobile phase. The total protein levels of the culture media were determined using a UV detector $(280 \mathrm{~nm}$ wavelength). The peak position of the target protein was specified by SDS-PAGE/CBB staining, and $\mathrm{gE}$ contents were calculated using a standard curve of purified $\mathrm{gE}$ protein. The lower detection limit of $\mathrm{gE}$ by SEC-HPLC was $150 \mathrm{mg} / \mathrm{L}$.

\section{Mouse immunization}

Six-week-old specific-pathogen-free female C57BL/6 mice (SLC, Shizuoka, Japan) were randomly assigned into groups of six and housed in a temperature- and humidity-controlled chamber with a 12-h light/dark cycle. The mice, either naïve or primed with live attenuated VZV (1/10 human dose of Zostavax ${ }^{\circledR}$, Merck, USA), were used for immunization as described previously (Wui et al. 2019). They were immunized twice at a 2-week interval via the intramuscular route with $5 \mu \mathrm{g}$ purified recombinant VZV gE plus $50 \mu \mathrm{g}$ of the liposomal adjuvant CIA09A in a total volume of $100 \mu \mathrm{L}$, as previously described (Wui et al. 2019). Control mice were administered phosphate-buffered saline (PBS). Four weeks later, blood samples were collected from the animals, allowed to clot at $4{ }^{\circ} \mathrm{C}$ overnight, and centrifuged. The sera were divided into aliquots and stored at $-70{ }^{\circ} \mathrm{C}$ until use. The spleen was removed from each animal and immediately used for assays. 
Determination of immune responses of mice to recombinant $\mathrm{gE}$ protein

VZV gE-specific IgG antibody titers in serum samples from individual mice were determined by endpoint dilution ELISA, as previously described (Han et al. 2012; Wui et al. 2019). Endpoint titers were defined as the highest serum dilutions that resulted in an absorbance value two times greater than that of nonimmune serum with a cut-off value of 0.1 and were expressed as group geometric mean titer $($ GMT) \pm standard deviation (SD) values of titers of the sera obtained from six mice in each group.

IFN- $\gamma$ levels secreted from mouse splenocytes were measured using cytokine sandwich ELISA assays, as previously described (Han et al. 2012). The frequency of gE-specific multifunctional $\mathrm{CD} 4^{+} \mathrm{T}$ cells expressing IFN- $\gamma$, TNF- $\alpha$ and/or IL- 2 was determined by intracellular cytokine staining (ICS) of the splenocytes of immunized mice followed by flow cytometry as previously described (Wui et al. 2019). A pool of $\mathrm{gE}$ peptides $(1.5 \mu \mathrm{g} / \mathrm{mL}$; JPT Peptide Technologies, Berlin, Germany), and VZV (500 pfu/mL) was used for ex vivo stimulation of splenocytes. Unstimulated medium control samples were included as negative controls. The results were presented as mean $\pm \mathrm{SD}$ values obtained from triplicate assays that used two spleens each.

\section{Statistical analysis}

SPSS 18.0 software (IBM) was used for the statistical analysis. Differences among experimental animal groups were analyzed using one-way ANOVAs with Tukey's multiple comparison tests. The PBS control group was excluded from statistical analysis. A twotailed Student's $t$-test was used to compare two experimental groups. $P$ values $<0.05$ were considered statistically significant.

\section{Results}

Selection of basal media optimal for $\mathrm{CHO}$ cell growth and VZV gE expression

In this study, we used three $\mathrm{CHO}$ cell clones that expressed high levels of recombinant VZV gE protein (\#23-125, \#23-136, and \#83-110). The clones were cultured using CD OptiCHO medium in flasks, and the culture supernatants were assayed for the expression levels of recombinant VZV gE by SDS-PAGE and immunoblot analysis using anti-VZV gE antibody. The results indicated that the three clones were similar in the expression levels of VZV gE and exhibited identical band patterns, both on the SDS-PAGE gels and immunoblots (Fig. S1 in Supplementary Information). To determine the immunological properties of $\mathrm{gE}$ proteins expressed in the $\mathrm{CHO}$ cell clones, we evaluated their immunogenicity in mice and compared the reactivity of induced mouse antibodies to VZV and cross-reactivity among the clones. Recombinant $\mathrm{gE}$ proteins were purified from the culture media of the $\mathrm{CHO}$ cell clones, and analyzed by SDS-PAGE and immunoblots (data not shown). Each gE preparation was then used to immunize mice, and serum antibody titers were measured against VZV as well as each $\mathrm{gE}$ preparation. The serum IgG antibody titers against each $\mathrm{gE}$ preparation were similar among the mouse groups, and no significant difference was observed in the reactivity between groups $(P>0.05)$ (Fig. 2). This result suggested that the $\mathrm{gE}$ proteins produced by the clones were immunologically identical. All three mouse antibodies raised against each clone also showed high reactivity to $\mathrm{VZV}$, and there was no difference in their antibody titers $(P>0.05)$,

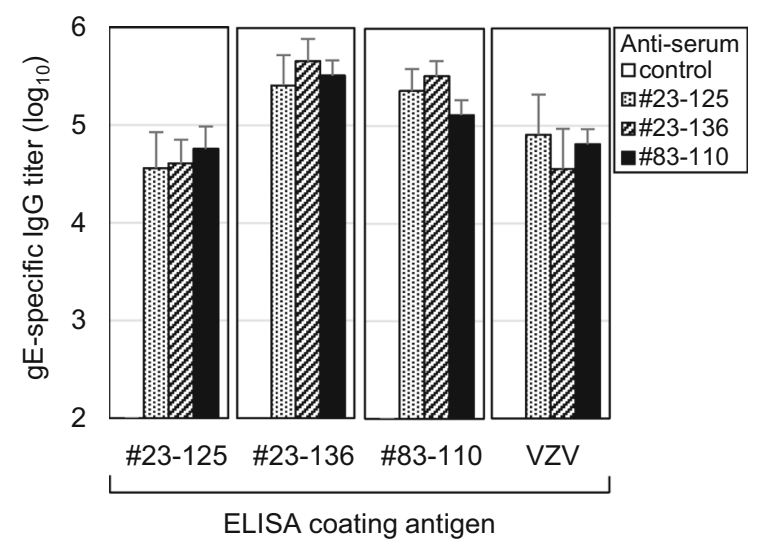

Fig. 2 Cross-reactivity of anti-sera raised against recombinant $\mathrm{gE}$ proteins expressed in $\mathrm{CHO}$ cell clones. Groups of naïve C57BL/6 mice $(n=6)$ were immunized with recombinant $\mathrm{gE}$ proteins expressed in $\mathrm{CHO}$ cell clones. Control mice were administered PBS. IgG titers of individual mouse sera were determined against each gE preparation and VZV by end-point dilution ELISA. Results are expressed as GMT \pm SD values of titers of individual sera obtained from six mice in each group. The IgG titers of all control sera are less than 100 
suggesting that the recombinant $\mathrm{gE}$ proteins were immunologically similar to the natural form of $\mathrm{gE}$ on VZV.

To determine the optimal basal medium for growth and $\mathrm{gE}$ expression of $\mathrm{CHO}$ cell clones, we screened 24 basal media for $\mathrm{CHO}$ cell culture. This group included 10 commercial media and 14 prototype media, which are presented in Table 1 . The $\mathrm{CHO}$ cell clones were cultured in each basal medium in microtiter plates for 7 days and were monitored for cell growth and $\mathrm{gE}$ expression. The results indicated that the VCD and VIA profiles of the three clones cultured in different basal media varied greatly (Fig. 3a, b). There were no common patterns between media, except that all three CHO clones had the highest cell growth in basal medium no. 6 (CDM4MAb; maximum cell density $8-15 \times 10^{6}$ cells/ mL).
To measure the levels of recombinant $\mathrm{gE}$ protein accumulated in the culture media, we set up SECHPLC analysis using gE preparation purified from clone \#23-125 and obtained a single peak (data not shown). The $\mathrm{gE}$ content in the HPLC peak was calculated using a standard curve obtained with purified $\mathrm{gE}$. The lower detection limit of $\mathrm{gE}$ by SECHPLC analysis was determined to be $150 \mathrm{mg} / \mathrm{L}$.

We then assessed the $\mathrm{gE}$ levels of the clones cultured in each of the 24 basal media using SECHPLC. Clone \#23-125 expressed gE in 22 out of 24 basal media tested and produced the highest level of $\mathrm{gE}$ protein among the three clones, regardless of basal medium type (Fig. 3c). The highest gE level of the clone was $410 \mathrm{mg} / \mathrm{L}$ when cultured in basal medium no. 18 (Preview CHO CD complete), followed by the culture grown with no. 24 (BalanCD CHO Growth A) (395 mg/L). No gE was detected in culture medium

Table 1 Basal media tested for batch culture

\begin{tabular}{|c|c|c|c|}
\hline Basal medium no. & Name of medium & Type of medium & Company \\
\hline 1 & KCM-8 & Prototype & Thermo Fisher Scientific \\
\hline 2 & КСM-9 & & \\
\hline 3 & CD FortiCHO & Commercial & \\
\hline 4 & CD OptiCHO & & \\
\hline 5 & $\mathrm{CDM} 4 \mathrm{CHO}$ & Commercial & GE Healthcare Life Sciences \\
\hline 6 & CDM4MAb & & \\
\hline 7 & CDM4PerMAb & & \\
\hline 8 & HyCell CHO Medium & & \\
\hline 9 & ActiPro & & \\
\hline 10 & $86825 \mathrm{C}$ & Prototype & Merck \\
\hline 11 & $83716 \mathrm{C}$ & & \\
\hline 12 & EX-CELL Advanced CHO & Commercial & \\
\hline 13 & BD-1 & Prototype & BD Biosciences \\
\hline 14 & BD-3 & & \\
\hline 15 & BD-12 & & \\
\hline 16 & BD-20 & & \\
\hline 17 & BD-21 & & \\
\hline 18 & Preview CHO CD complete & & \\
\hline 19 & PowerCHO-2 CD & Commercial & Lonza \\
\hline 20 & Power $\mathrm{CHO}$ advance & Prototype & \\
\hline 21 & JX G001 & Prototype & Irvine Scientific \\
\hline 22 & JX G006 & & \\
\hline 23 & JX G020 & & \\
\hline 24 & BalanCD CHO Growth A & Commercial & \\
\hline
\end{tabular}


(a)
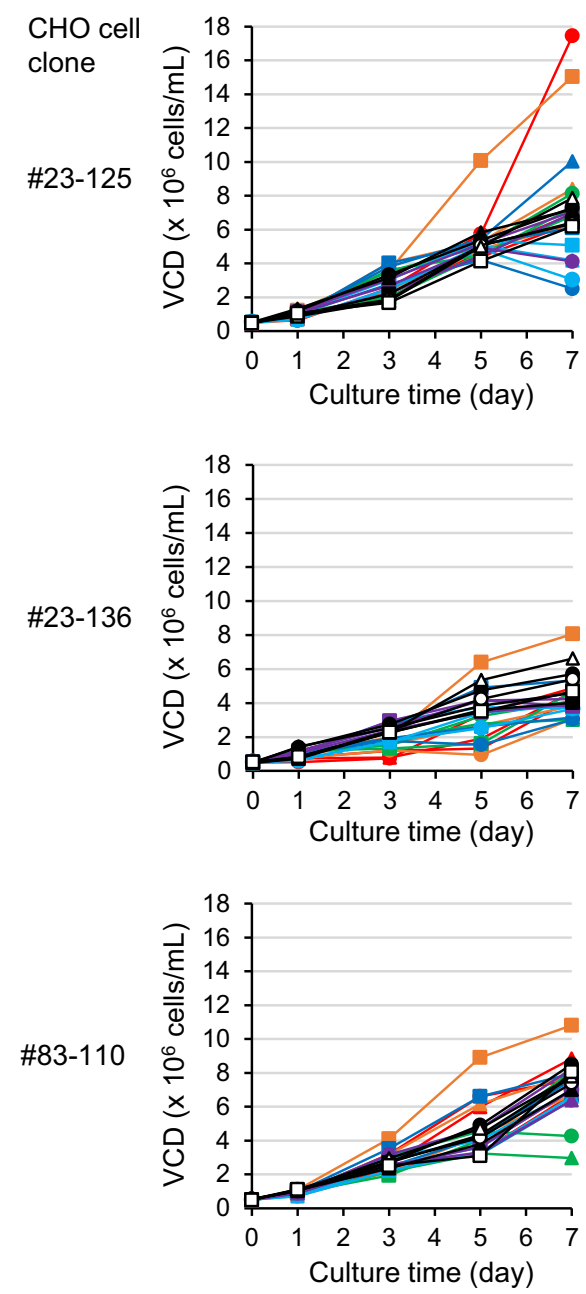

(b)
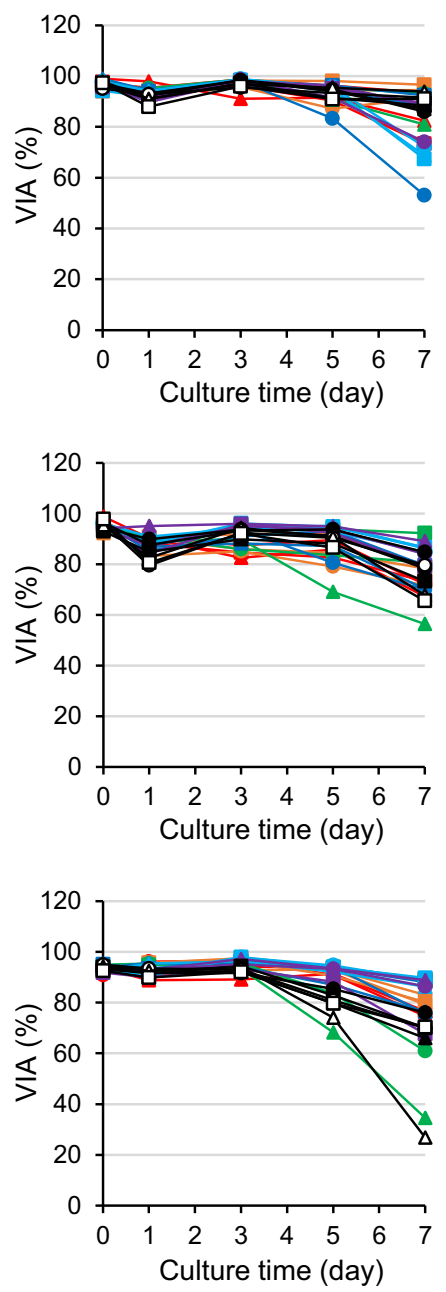

(c)
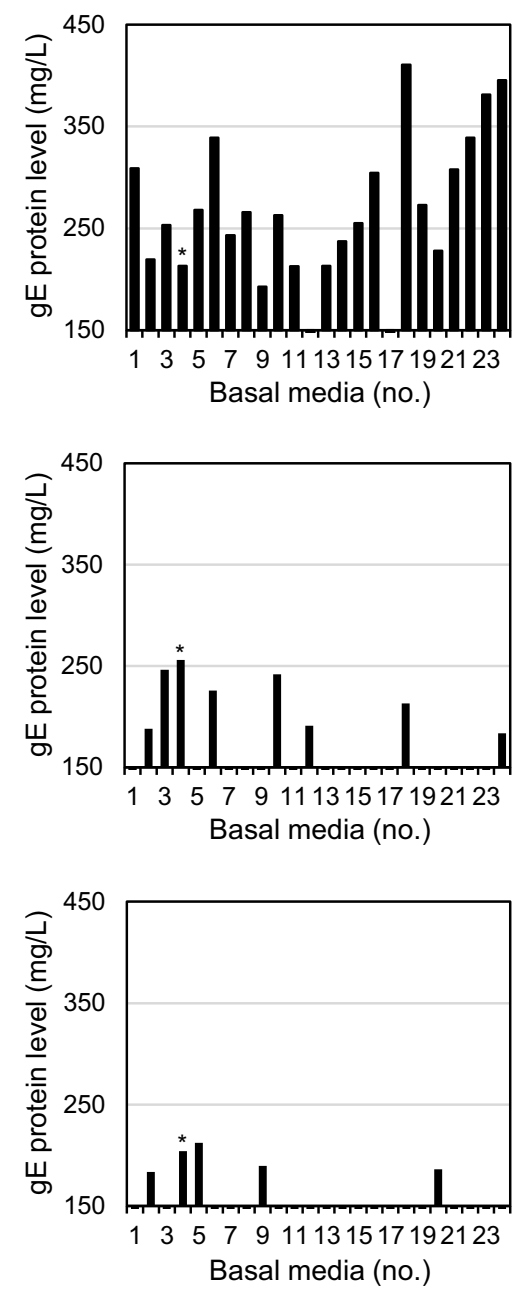

Basal media (no.)

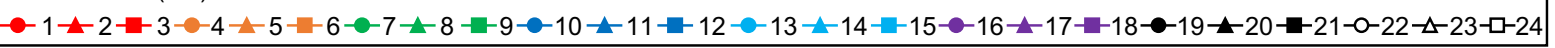

Fig. 3 Growth profiles and VZV gE expression levels of CHO cell clones cultured in various basal media. Three $\mathrm{CHO}$ cell clones were cultured in 24 different basal media in microtiter plates for 7 days. The cultures were assessed for VCD (a) and VIA (b) at days $0,1,3,5$, and 7 . Levels of VZV gE protein in

no. 12 (EX-CELL Advanced CHO) or no. 17 (BD-21). In contrast to \#23-125, the clones \#23-136 and \#83110 produced detectable levels of $\mathrm{gE}$ in 8 and in 5 media, respectively, out of the 24 basal media tested. Furthermore, their $\mathrm{gE}$ expression levels were considerably lower than clone \#23-125. The highest gE level of \#23-136 was $255 \mathrm{mg} / \mathrm{L}$ with basal medium no. 4 , while clone \#83-110 produced $210 \mathrm{mg} / \mathrm{L}$ with medium no. 5 (CDM4CHO). Given that these two clones individual culture media were determined at day 7 by SECHPLC analysis (c). The y-axis of the graphs starts at $150 \mathrm{mg} / \mathrm{L}$ of $\mathrm{gE}$ protein that is the lower detection limit of $\mathrm{gE}$ by SECHPLC. *Original culture medium (basal medium no. 4; CD OptiCHO)

produced significant levels of $\mathrm{gE}$ in the original medium (no. 4; CD OptiCHO), this result was somewhat surprising. It is likely that these clones expressed $\mathrm{gE}$ to levels below the detection limit of the assay $(150 \mathrm{mg} / \mathrm{L})$ in most of the media tested. Based on these results, basal media, no. 18 and no. 24 giving the highest productivity were chosen for further study. Basal media no. 3 (CD FortiCHO) which yielded a fairly good productivity for both \#23-125 and \#23-136 
were also selected for comparison. The clone with the highest productivity, \#23-125, was chosen as the production cell line.

Selection of feed medium optimal for $\mathrm{CHO}$ cell growth and VZV gE expression

To determine the optimal medium conditions for fedbatch cultures, we tested 13 commercial feed media that are listed in Table 2. The selected CHO clone \#23125 was fed-batch cultured in the three selected basal media in combination with each feed medium in microtiter plates for 11 days. Cell growth profiles were monitored every 2 days. VCD reached its peak at day 7 or 9 in most of the cultures, and then decreased regardless of basal medium type (data not shown). Among the 13 feed media, either no. 5 (Cell boost 5) or no. 7 (EX-CELL Advanced CHO Feed 1) gave the best growth profiles, based on the VCD and VIA results for the cell cultures. The levels of recombinant $\mathrm{gE}$ protein accumulated in the culture media were measured by SEC-HPLC. The highest gE levels were obtained in the cultures supplied with feed medium no. 7; the yield was $>600 \mathrm{mg} / \mathrm{L}$ culture, regardless of basal medium type (Fig. 4). A combination of feed medium no. 7 with basal medium no. 24 was particularly effective in supporting gE production, with $\mathrm{gE}$ level of $870 \mathrm{mg} / \mathrm{L}$ culture. This level was more than two times higher than that obtained from batch culture with basal medium no. 24. Based on the results for cell growth profile and target protein productivity, feed medium no. 7 was chosen as the production medium for the $\mathrm{CHO}$ cell clone.

Scale-up cultures of the $\mathrm{CHO}$ cell clone using optimized medium conditions

Next, we carried out fed-batch cultures of the $\mathrm{CHO}$ clone in a flask using the selected medium conditions. Clone \#23-125 was cultured in either basal medium no. 3 , no. 18 , or no. 24 , and was fed with feed medium no. 7 on days $3,5,7,9$, and 11 . VCD and VIA were assessed every day for 14 days. The gE levels present in the culture media were determined at day 14. The VCD of all three cultures reached a peak at day 10 and then slowly declined thereafter (Fig. 5a). As for VIA, all three cultures maintained nearly $100 \%$ viability until day 11 with a slight decrease thereafter. Among the three fed-batch cultures, basal medium no. 24 resulted in the highest VCD $\left(1.7 \times 10^{7}\right.$ cells $\left./ \mathrm{mL}\right)$, followed by basal medium no. 3. Flask cultures with feed medium no. 7 increased target protein productivity by 1.2 to 1.5 -fold, compared with those obtained from the cultures in microtiter plates. The highest $\mathrm{gE}$ protein level was obtained when the cells were cultured in basal medium no. 24 with feed medium no. 7 (1,270 mg/L culture) (Fig. $5 b)$. The gE productivity per cell of clone \#23-125 was 66 to 107 pg in fed-batch flask cultures, which was 1.5-1.8 times higher than those of microtiter plate cultures in the three basal media (Fig. S2 and Fig. 5b). The cell density of the clone was also increased by 1.2 to 2.2 times. Therefore, both increase in cell density and
Table 2 Feed media tested for fed-batch culture

\begin{tabular}{lll}
\hline Feed medium no & Name of medium & Company \\
\hline 1 & Cell boost 1 & GE Healthcare Life Sciences \\
2 & Cell boost 2 & \\
3 & Cell boost 3 & \\
4 & Cell boost 4 & \\
5 & Cell boost 5 & \\
6 & Cell boost 6 & Merck \\
7 & EX-CELL Advanced CHO Feed 1 & Lonza \\
8 & CHO Xtreme Feed & Irvine Scientific \\
9 & BalanCD CHO Feed 1 & \\
10 & BalanCD CHO Feed 2 & Thermo Fisher Scientific \\
11 & BalanCD CHO Feed 3 & \\
12 & Feed B+ & \\
13 & Feed C + & \\
\hline
\end{tabular}


(a)

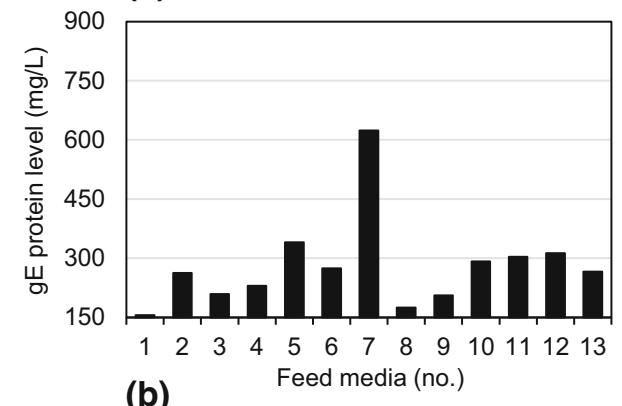

(b)

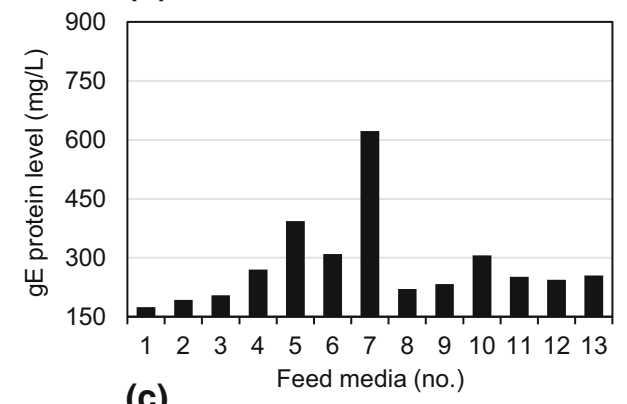

(c)

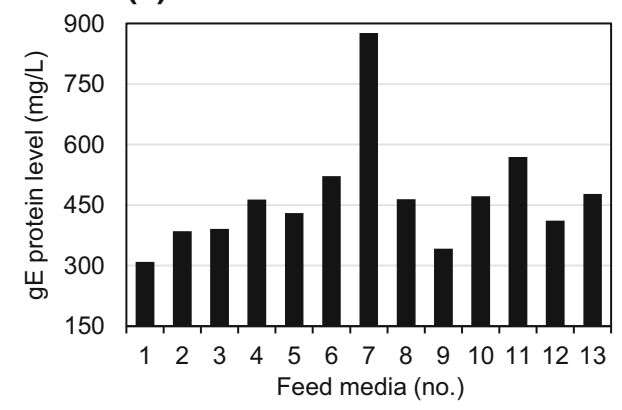

Fig. 4 Effects of feed media on gE expression of the selected CHO cell clone. Clone \#23-125 was cultured in basal media no. 3 (a), no. 18 (b), or no. 24 (c) in microtiter plates and fed with 13 different feed media, as described in Materials and Methods, and the gE levels of culture media were determined by SEC-HPLC. The $y$-axis of the graphs starts at $150 \mathrm{mg} / \mathrm{L}$ of gE protein that is the lower detection limit of $\mathrm{gE}$ by SEC-HPLC analysis

higher $\mathrm{gE}$ productivity per cell contributed to the increase in total $\mathrm{gE}$ productivity of clone \#23-125 in fed-batch flask cultures. Based on these results, we selected the combination of basal medium no. 24 and feed medium no. 7 as the production media for the VZV gE production cell line \#23-125.

For the large-scale production culture, we used a wave bag culture system. The clone \#23-125 cells were cultured in $15 \mathrm{~L}$ basal medium no. 24 in a $20 \mathrm{~L}$ wave bag. They were supplied with feed medium no. 7 on days $2,4,6,8$, and 10 . An aliquot of the culture medium was collected every day and assayed for VIA, (a)

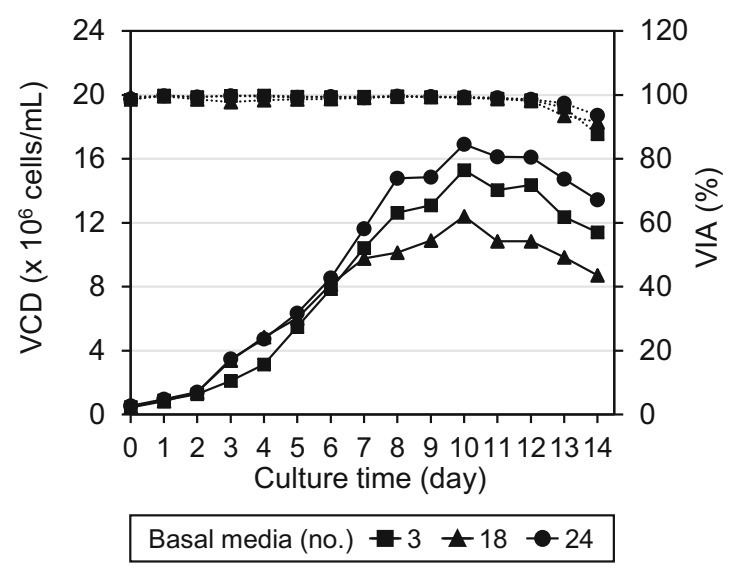

(b)

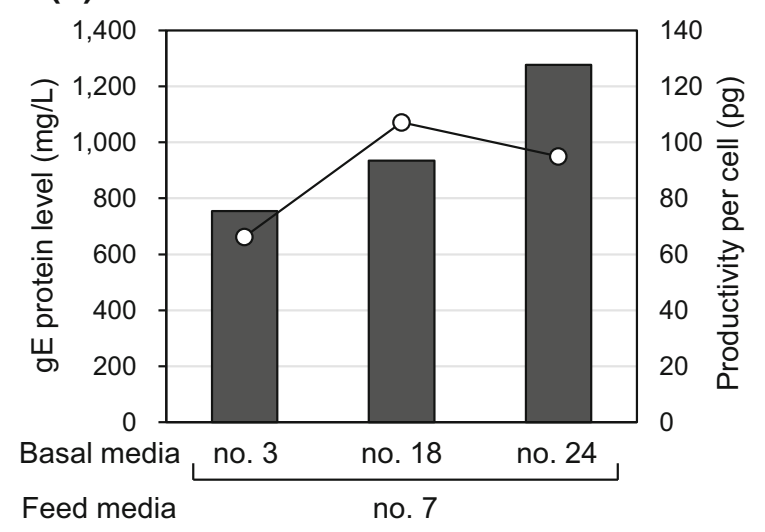

Fig. 5 Culture profiles and gE productivity of the selected clone in a flask culture. Clone \#23-125 was cultured in $200 \mathrm{~mL}$ basal media (no. 3, 18, or 24) in a flask for 14 days. Cells were fed with feed medium no. 7 at days 3, 5, 7, 9, and 11. VCD (solid line) and VIA (dotted line) of each culture were determined every day (a), and VZV gE levels of individual culture media (filled square) were determined at day 14, and the $\mathrm{gE}$ productivity per cell of each clone (open circle) was calculated (b)

VCD, and levels of gE protein secreted into the culture medium. In preliminary experiments, we found that once VIA decreased below 90\%, VCD dropped rapidly and there was no further increase in $\mathrm{gE}$ levels (data not shown). Therefore, we maintained wave bag cultures until the culture VIA values were greater than 90\%; the cultures were then terminated. The cell density reached the maximum level at day 12 , and then declined (Fig. 6a). To follow-up gE protein levels during the culture period, samples of medium were removed every day and analyzed by SEC-HPLC. The $\mathrm{gE}$ protein was detected from day 6 and gradually 
(a)

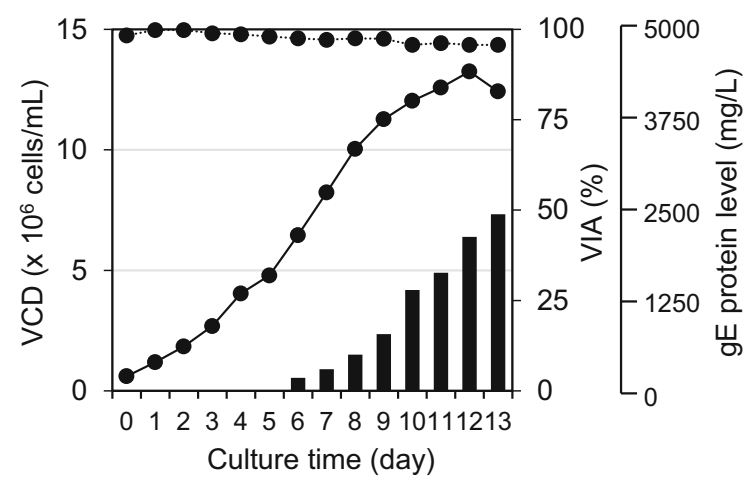

(b)

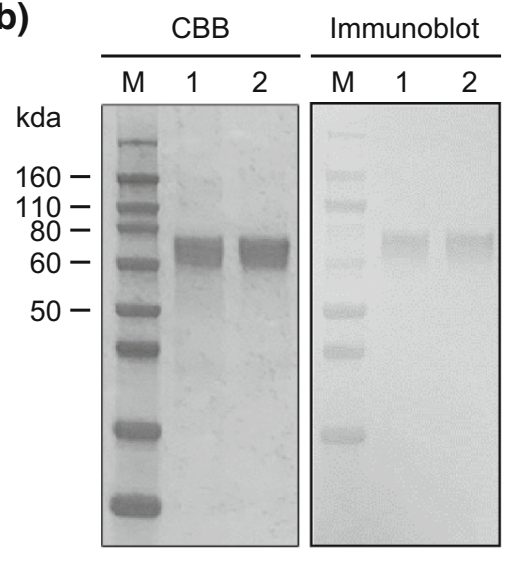

Fig. 6 Growth profile and $\mathrm{gE}$ protein productivity of the selected $\mathrm{CHO}$ clone fed-batch cultured in a wave bag bioreactor. a Clone \#23-125 was cultured in basal medium no. 24 in a wave bag bioreactor system for 13 days. Cells were fed with feed medium no. 7 at days 2, 4, 6, and 8. VCD (solid line) and VIA (dotted line) of the culture were determined every day, and $\mathrm{gE}$ protein levels (bar) were measured by SEC-HPLC. b Recombinant $\mathrm{gE}$ protein was purified from the culture media harvested at day 13, as described in Materials and Methods. An aliquot of culture medium and purified gE protein were subjected to SDSPAGE/CBB staining $(1 \mu \mathrm{g}$ protein/well $)$ and immunoblot analysis $(0.1 \mu \mathrm{g}$ protein/well $)$. The results represent at least six independent experiments with similar results. Lanes $\mathrm{M}$, protein size markers; 1 , culture medium; 2 , purified $\mathrm{gE}$ protein

increased until the end of the culture period. The final $\mathrm{gE}$ protein level on day 13 was $2440 \mathrm{mg} / \mathrm{L}$ culture, which was 1.9 times higher than that obtained in flask cultures.

To verify characteristics of $\mathrm{gE}$ protein produced in large-scale cultures, we purified $\mathrm{gE}$ by anion exchange chromatography and analyzed by SDS-PAGE/CBB staining and immunoblot analysis. The SDS-PAGE results indicated that the purified $\mathrm{gE}$ protein had an expected size of $61.4 \mathrm{kDa}$ with a purity greater than 98\% (Fig. 6b). Furthermore, the immunoblot with anti-VZV gE antibody displayed a single band at the position corresponding to $\mathrm{gE}$. These results confirmed the identity of the recombinant $\mathrm{gE}$ protein produced by the selected $\mathrm{CHO}$ clone, and we decided to determine the immunogenicity of the purified $\mathrm{gE}$ protein.

Evaluation of immunogenicity of recombinant $\mathrm{gE}$ protein produced in optimal culture medium conditions

Finally, we evaluated the immunogenicity of the recombinant VZV gE protein in mice. Mice primed with VZV were immunized with recombinant $\mathrm{gE}$ plus adjuvant CIA09A, and immune responses were assessed. A group of mice administered LAV was included for comparison. The serum IgG antibody titers of the mice receiving adjuvanted recombinant $\mathrm{gE}$ protein were 250 times higher than those of the control group that had considerable levels of gE-specific $\mathrm{IgG}$ antibodies due to VZV-priming (Fig. 7a). It was 30 times higher when compared with those of the LAVvaccinated group.

The cellular immunity of the immunized mice to VZV gE was also determined by measuring splenic IFN- $\gamma$ cytokine levels induced upon ex vivo stimulation with VZV as well as a pool of VZV gE peptides. When treated with medium only, IFN- $\gamma$ secretion was not detected in any of the experimental groups (Fig. 7b). After stimulation with gE peptides, however, the adjuvanted gE group showed a significantly increased IFN- $\gamma$ level, indicating an induction of $\mathrm{gE}$ specific cellular immune response. VZV stimulation also induced a high IFN- $\gamma$ response in this group. In contrast, the LAV-treated group showed little IFN- $\gamma$ secretion in response to either gE peptides or VZV. The frequency of gE-specific multifunctional CD $4^{+} \mathrm{T}$ cells was also determined by ICS of immune splenocytes followed by flow cytometry. The mice administered adjuvanted $\mathrm{gE}$ exhibited a significantly higher frequency of multifunctional $\mathrm{CD}^{+}{ }^{+} \mathrm{T}$ cells as compared to LAV-immunized mice (Fig. 7c). Taken together, these results demonstrated that the recombinant $\mathrm{gE}$ protein, when combined with a proper adjuvant, is able to induce both humoral and cellular immune responses, suggesting the potential of the recombinant $\mathrm{gE}$ protein as antigen for $\mathrm{HZ}$ vaccine. 
(a)

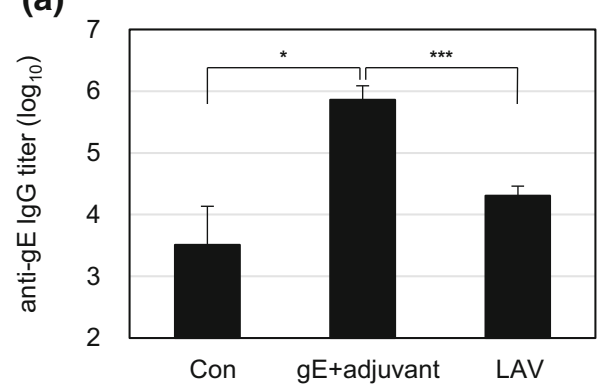

(b)

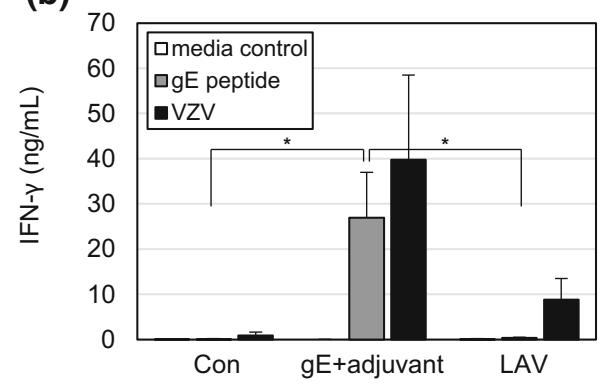

(c)

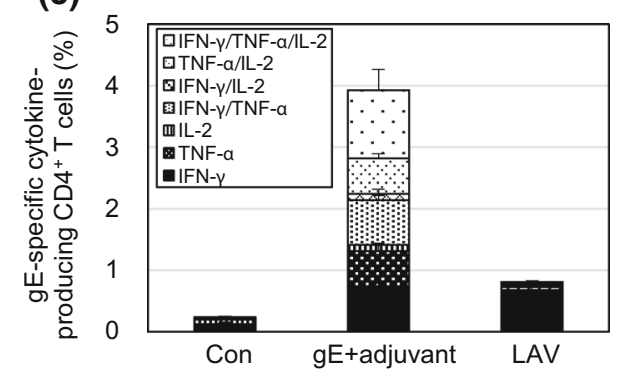

Fig. 7 Evaluation of immunogenicity of recombinant VZV gE protein in mice. Mice primed with VZV were immunized with recombinant $\mathrm{gE}$ protein plus CIA09A ( $\mathrm{gE}+$ adjuvant). Control mice were administered PBS, and a group of mice given LAV was included for comparison. Anti-gE IgG antibody titers of individual mouse sera were determined, and results are expressed as GMT $\pm \mathrm{SD}$ of values obtained from six mice in each group (a). Splenocytes harvested from immunized mice were ex vivo stimulated with a pool of gE peptides or VZV. The levels of IFN- $\gamma$ secreted into the culture media $(\mathbf{b})$ and the frequency of IFN- $\gamma$, TNF- $\alpha$ and/or IL-2-producing $\mathrm{CD}^{+}{ }^{+} \mathrm{T}$ cells (c) were determined by sandwich ELISA and ICS, respectively. Results are presented as the mean \pm SD of values obtained from triplicate assays that used two spleens each. Statistical significance between experimental groups; $* P<0.05$; $* * * P<0.001$. Data shown are representative of more than three experiments with similar results

\section{Discussion}

This study was performed to optimize culture conditions for growth and protein productivity of $\mathrm{CHO}$ cell clones expressing recombinant $\mathrm{VZV} \mathrm{gE}$ antigen. We screened 24 basal media and 13 feed media using a high-throughput culture system. The clone with the highest productivity was selected and cultured in a scale-up fed-batch culture in a wave bag bioreactor using the optimized media. The final gE productivity of the selected clone was $2440 \mathrm{mg} / \mathrm{L}$ culture media, being 11.5 times greater than that obtained with the original medium conditions. Immunogenicity of the purified recombinant $\mathrm{gE}$ protein was confirmed in a mouse model.

In the bio-pharmaceutical industry, $\mathrm{CHO}$ cells are widely used as mammalian expression system for recombinant protein production. Many commercial media are currently available for $\mathrm{CHO}$ cell culture and protein production (Ma et al. 2009; Rodrigues et al. 2012). However, the intrinsic characteristics of animal cells may be changed due to expression of the proteins of inserted genes, and therefore, no single medium would be suitable for all $\mathrm{CHO}$ cell clones. Optimal medium conditions should be established by screening culture media for each $\mathrm{CHO}$ cell clone and target protein (Ozturk and Hu 2005; Pan et al. 2017; Reinhart et al. 2015; Rodrigues et al. 2012). Like many other previous studies, we observed that $\mathrm{CHO}$ clones were very different in cell growth and productivity depending on the type of basal and feed media. In this study, BalanCD CHO Growth A medium that gave the highest productivity for the selected clone and chosen as basal medium. In this case, BalanCD CHO Feed 1, 2 , and 3 are recommended as feed media by the manufacturer. Screening of 13 feed media for the $\mathrm{CHO}$ clone, however, demonstrated that the combination of BalanCD CHO Growth A and EX-CELL Advanced CHO Feed 1 as basal and feed media, respectively, is the most optimal media condition for growth and productivity in fed-batch cultures of CHO-DG44 clones expressing VZV gE. The results of this study demonstrated that it is essential to select optimal media according to the unique characteristics of production cell lines and target proteins for the commercial production of biopharmaceuticals in animal cells.

For $\mathrm{HZ}$ vaccines, cell-medicated immunity, but not VZV-specific antibody, plays a pivotal role in preventing $\mathrm{HZ}$ and reducing the severity and incidence of HZ-associated PHN (Cunningham and Levin 2018; Levin et al. 2008). VZV-specific T-cell-mediated immunity, as determined by the frequency of IFN- $\gamma$ - 
producing cells, is strongly correlated to the protective efficacy of the vaccine (Levin et al. 2008). In addition, multifunctional $\mathrm{CD} 4^{+} \mathrm{T}$ cells co-expressing IFN- $\gamma$, IL-2, and TNF- $\alpha$ have been shown to play a role in preventing $\mathrm{HZ}$ occurrence and, therefore, used as an indicator of the efficacy of an $\mathrm{HZ}$ vaccine in a clinical trial (Cunningham et al. 2018; Schub et al. 2015). The results of this study showed that recombinant $\mathrm{gE}$ protein produced in the optimized culture conditions was able to induce VZV-specific T-cell medicated immunity as well as antibody response. Induction of multifunctional $\mathrm{CD}^{+}{ }^{+} \mathrm{T}$ cells by adjuvanted recombinant $\mathrm{gE}$ also supported the potential of the $\mathrm{gE}$ protein as antigen for an $\mathrm{HZ}$ subunit vaccine.

In conclusion, we successfully developed optimal culture medium conditions for $\mathrm{CHO}$ cell clones expressing recombinant VZV gE protein. BalanCD CHO Growth A and EX-CELL Advanced CHO Feed 1 were chosen as basal and feed media, respectively, for fed-batch culture production of VZV gE protein. We confirmed that purified recombinant $\mathrm{gE}$ protein induced both humoral and cellular immune responses that were specific for VZV as well as gE. The optimized media condition obtained in this study is used in a Good Manufacturing Practices compliant facility to produce VZV gE antigen for an $\mathrm{HZ}$ subunit vaccine, which is under Phase I clinical trial. We believe that this study would provide valuable insights on culture media optimization for $\mathrm{CHO}$ cells producing a recombinant vaccine antigen.

Funding This study was supported by Grants from the Korean Health Technology R\&D Project, Ministry of Health \& Welfare, Republic of Korea (Grant No. HI14C2664).

Data availability Data and material are available upon reasonable request.

\section{Declarations}

Conflict of interest KSK and SAP are employees of EyeGene. NGL is a scientific advisor for EyeGene. KSK, SAP, and NGL are inventors of EyeGene-owned patents related to $\mathrm{HZ}$ subunit vaccine containing VZV gE vaccine. The other authors have no conflict of interests.

Consent for publication All authors agreed to publication.

Ethical approval The animal experimental protocols were reviewed and approved by the Sejong University Institutional Animal Care and Use Committee (Approval Number: SJ20150301).

\section{References}

Chlibek R, Pauksens K, Rombo L et al (2016) Long-term immunogenicity and safety of an investigational herpes zoster subunit vaccine in older adults. Vaccine 34:863-868. https://doi.org/10.1016/j.vaccine.2015.09. 073

Cunningham AL, Levin MJ (2018) Herpes zoster vaccines. J Infect Dis 218:S127-S133. https://doi.org/10.1093/ infdis/jiy382

Cunningham AL, Heineman TC, Lal H et al (2018) Immune responses to a recombinant glycoprotein $\mathrm{E}$ herpes zoster vaccine in adults aged 50 years or older. J Infect Dis 217:1750-1760. https://doi.org/10.1093/infdis/jiy095

Hales CM, Harpaz R, Ortega-Sanchez I et al (2014) Update on recommendations for use of herpes zoster vaccine. MMWR Morb Mortal Wkly Rep 63:729-731

Han JE, Wui SR, Park SA et al (2012) Comparison of the immune responses to the CIA06-adjuvanted human papillomavirus L1 VLP vaccine with those against the licensed HPV vaccine Cervarix ${ }^{\mathrm{TM}}$ in mice. Vaccine 30:4127-4134. https://doi.org/10.1016/j.vaccine.2012.04.079

James SF, Chahine EB, Sucher AJ et al (2018) Shingrix: the new adjuvanted recombinant herpes zoster vaccine. Ann Pharmacother 52:673-680. https://doi.org/10.1177/ 1060028018758431

Jayapal KR, Wlaschin KF, Hu WS et al (2007) Recombinant protein therapeutics from $\mathrm{CHO}$ cells - 20 years and counting. Chem Eng Prog 103:40-47

Kelley B (2009) Industrialization of mAb production technology: the bioprocessing industry at a crossroads. MAbs 1:443-452. https://doi.org/10.4161/mabs.1.5.9448

Kyriakopoulos S, Kontoravdi C (2014) A framework for the systematic design of fed-batch strategies in mammalian cell culture. Biotechnol Bioeng 111:2466-2476. https:// doi.org/10.1002/bit.25319

Lal H, Cunningham AL, Godeaux O et al (2015) Efficacy of an adjuvanted herpes zoster subunit vaccine in older adults. N Engl J Med 372:2087-2096. https://doi.org/10.1056/ NEJMoa1501184

Levin MJ, Murray M, Rotbart HA et al (1992) Immune response of elderly individuals to a live attenuated varicella vaccine. J Infect Dis 166:253-259. https://doi.org/10.1093/infdis/ 166.2 .253

Levin MJ, Oxman MN, Zhang JH et al (2008) Varicella-zoster virus-specific immune responses in elderly recipients of a herpes zoster vaccine. J Infect Dis 197:825-835. https:// doi.org/10.1086/528696

Lu F, Toh PC, Burnett I et al (2013) Automated dynamic fedbatch process and media optimization for high productivity cell culture process development. Biotechnol Bioeng 110:191-205. https://doi.org/10.1002/bit.24602

Ma NN, Ellet J, Okediadi C et al (2009) A single nutrient feed supports both chemically defined NSO and $\mathrm{CHO}$ fed-batch processes: improved productivity and lactate metabolism. Biotechnol Prog 25:1353-1363. https://doi.org/10.1002/ btpr.238

Oxman MN, Levin MJ, Johnson GR et al (2005) A vaccine to prevent herpes zoster and postherpetic neuralgia in older 
adults. N Eng1 J Med 352:2271-2284. https://doi.org/10. 1056/NEJMoa051016

Ozturk SS, Hu W-S (2005) Cell culture technology for pharmaceutical and cell-based therapies. CRC Press, New York

Pan X, Streefland M, Dalm C et al (2017) Selection of chemically defined media for $\mathrm{CHO}$ cell fed-batch culture processes. Cytotechnology 69:39-56. https://doi.org/10.1007/ s10616-016-0036-5

Reinhart D, Damjanovic L, Kaisermayer C et al (2015) Benchmarking of commercially available $\mathrm{CHO}$ cell culture media for antibody production. Appl Microbiol Biotechnol 99:4645-4657. https://doi.org/10.1007/s00253-015-65144

Ritacco FV, Wu YQ, Khetan A (2018) Cell culture media for recombinant protein expression in Chinese hamster ovary (CHO) cells: history, key components, and optimization strategies. Biotechnol Prog 34:1407-1426. https://doi.org/ 10.1002/btpr.2706

Rodrigues ME, Costa AR, Henriques M et al (2012) Comparison of commercial serum-free media for $\mathrm{CHO}-\mathrm{K} 1$ cell growth and monoclonal antibody production. Int $\mathrm{J}$ Pharm 437:303-305. https://doi.org/10.1016/j.ijpharm.2012.08. 002
Schub D, Janssen E, Leyking S et al (2015) Altered phenotype and functionality of varicella zoster virus-specific cellular immunity in individuals with active infection. J Infect Dis 211:600-612. https://doi.org/10.1093/infdis/jiu500

Urlaub G, Kas E, Carothers AM et al (1983) Deletion of the diploid dihydrofolate reductase locus from cultured mammalian cells. Cell 33:405-412. https://doi.org/10.1016/ 0092-8674(83)90422-1

Wui SR, Kim KS, Ryu JI et al (2019) Efficient induction of cellmediated immunity to varicella-zoster virus glycoprotein $\mathrm{E}$ co-lyophilized with a cationic liposome-based adjuvant in mice. Vaccine 37:2131-2141. https://doi.org/10.1016/j. vaccine. 2019.02 .048

Wurm FM (2004) Production of recombinant protein therapeutics in cultivated mammalian cells. Nat Biotechnol 22:1393-1398. https://doi.org/10.1038/nbt1026

Zerboni L, Sen N, Oliver SL et al (2014) Molecular mechanisms of varicella zoster virus pathogenesis. Nat Rev Microbiol 12:197-210. https://doi.org/10.1038/nrmicro3215

Publisher's Note Springer Nature remains neutral with regard to jurisdictional claims in published maps and institutional affiliations. 